\title{
Histopathology of Polyps and Its Clinical Correlation in Sample of Iraqi Patients Undergoing Colonoscopic Examination
}

\author{
Khalid Abdulla Al-Khazraji ${ }^{1}$, Mohammed Kamal Hashim², Mahmood Kamal Hashim³, \\ Wissam Khudhair Abbas ${ }^{4} \&$ Mohammed Mousa Dhahir \\ ${ }^{1}$ Professor of Gastroenterology, College of Medicine, Baghdad University, Iraq \\ ${ }^{2}$ Department of Surgery, Al-Noman Teaching hospital, Al-Iraqia Medical College, Iraq \\ ${ }^{3}$ Department of Dermatology, Baghdad Teaching Hospital, Iraq \\ ${ }^{4}$ Al-Mustansiriya University, College of Medicine, Iraq \\ ${ }^{5}$ Department of Internal Medicine, Baghdad Teaching Hospital, Iraq \\ Correspondence: Khalid Abdulla Al-Khazraji, MBCHB, MD, CAMB, FRCP, FACP, Professor of \\ Gastroenterology, College of Medicine, Baghdad University, Iraq.
}

Received: May 9, 2020 Accepted: February 18, 2021 Online Published: March 15, 2021

doi:10.5539/gjhs.v13n4p106 URL: https://doi.org/10.5539/gjhs.v13n4p106

\begin{abstract}
Background /Aims: Colorectal cancer is the third most common cancer in 2018, the objective of our study was to describe the types and patterns of colorectal polyps in patients presenting to a tertiary care referral center in Baghdad. We also assessed the polyp detection rate (PDR) and adenoma detection rate (ADR).

Patients \& Methods: This is single-institution, descriptive cross-sectional study of consenting 103 patients who had colonoscopy done at the Endoscopy Unit of Baghdad teaching hospital, IRAQ from the 1st of June 2018 to 31 st of March 2019 after taking verbal consent, The data collected included: Age, sex, Family history of colorectal malignancies and indication for the current colonoscopy.

Results: One thousand and thirty patients were included in the study with a mean age of 44 years $(\mathrm{SD}=16)$, with 560 males representing $54.4 \%$ and 470 females representing $45.66 \%$.The polyp detection rate in colonoscopies was $19.4 \%$ and the adenoma detection rate was $13.6 \%$. Polyps were found and removed in 200 patients, $40 \%$ of the removed polyps were tubular adenomas, tubulovillous adenomas in $20 \%$, villous adenomas in $10 \%$, hyperplastic polyps in 5\%. The majority of the polyps were in the distal colon in $80 \%$ of patients with polyps.
\end{abstract}

Conclusions: The polyp detection rate was (19.4\%) and adenoma detection rate was (13.6\%). The majority of polyps were detected in distal colon.

Keywords: Colonic polyps, site, Pattern. Histopathology

\section{Introduction and Literature Review}

According to the WHO, colorectal cancer is the third most common cancer in 2018, both sexes, all ages. Almost 55\% of the cases occur in more developed regions but with less mortality than in less developed regions (The global cancer observatory. 2018).

Colorectal cancer (CRC) is one of the few diseases for which screening programs have shown to be efficacious in decreasing both the incidence as well as the mortality. Randomized controlled trials have demonstrated that repetitive fecal occult blood testing (FOBT) reduces the mortality from CRC by $16 \%$, while once-only flexible sigmoidoscopy reduces CRC incidence and mortality by $18 \%$ and $28 \%$, respectively (Garborg, Holme, Loberg, Kalager, Adami, \& Bretthauer, 2013).

Colorectal polyp (CP) is a grossly visible protrusion from the mucosal of the large bowel. They may be classified pathologically as a nonneoplastic hamartoma (e.g. juvenile polyp), a hyperplastic mucosal proliferation (hyperplastic polyp), or an adenomatous polyp .Only adenomas are clearly premalignant, and only a minority of adenomatous polyps evolve into cancer (Anthony et al., 2018).

Clinically, the probability of an adenomatous polyp becoming a cancer depends on:

1. The gross appearance of the lesion, 
2. The polyps histological features.

3. The polyp(s) size.

Polyps may be pedunculated (stalked) or sessile (flat-based) adenomatous or serrated (Figure 1).

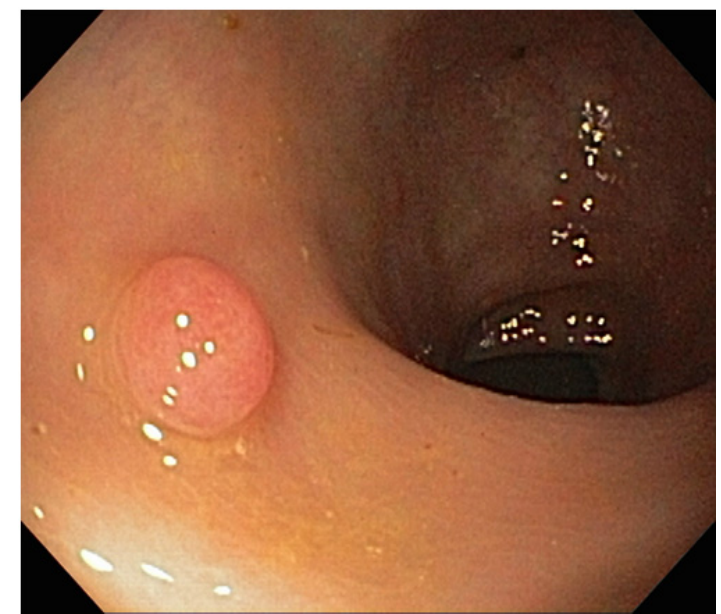

(A)Sessile serrated adenoma

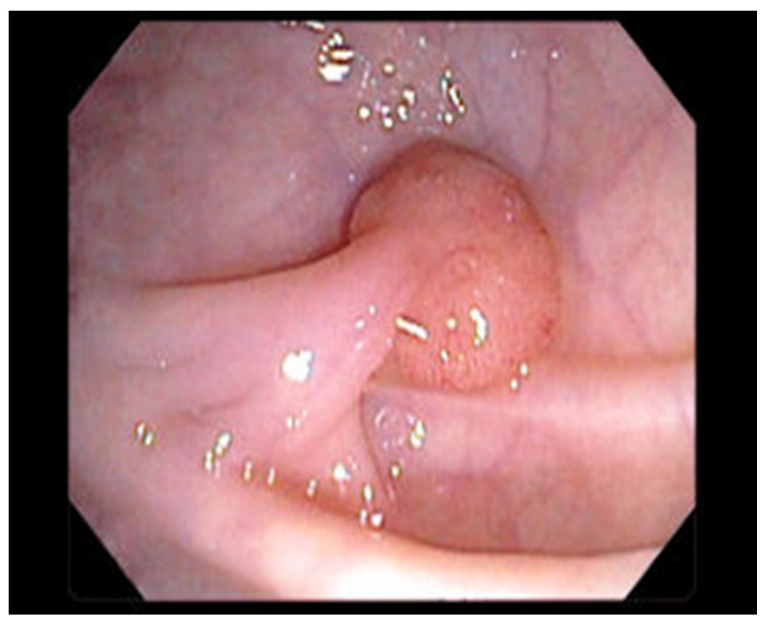

(B) pedunculated tubular adenoma

Figure 1. Gross appearance of polyp with pedunculated and sessile polyp (A and B)

Invasive cancers develop more frequently in sessile, serrated polyps. Colonic polyps may be divided into 2 major groups: neoplastic (adenomas and carcinomas) and non-neoplastic. The adenomas and carcinomas share a characteristic - cellular dysplasia — but they may be subdivided according to the relative prominence of certain microscopic features. Histologically, adenomatous polyps may be (1) tubular, (2) villous or (3) tubulovilous. The increased realization that serrated polyps also have malignant potential now permits classifying them as neoplastic polyps (Anthony et al., 2018).

Submucosal lesions also can impart a polypoid appearance to the overlying mucosa and therefore are briefly mentioned even though they are not true polyps (Feldman \& Friedman, 2016).

Adenomas are often categorized into 3 size groups: smaller than $1 \mathrm{~cm}$ (small), 1 to $2 \mathrm{~cm}$ (moderate), and larger than $2 \mathrm{~cm}$ (large) (Muto, Bussey, \& Morson, 1975)

Eighty percent of colorectal cancers (CRCs) arise from preexisting adenomas (Nouraie, Hosseinkhah, Brim, Zamanifekri, Smoot, \& Ashktorab, 2010).

In the era of screening colonoscopy, the colorectal polyp detection rate is increasing. Colonoscopy continues to be considered as the gold standard screening tool for colon cancer prevention because it enables the removal of precancerous adenomas (Visovan, Tantau, Ciobanu, Pascu, \& Tantau, 2014).

When calculating the adenoma detection rate (ADR), the numerator included all colonoscopies where at least one polyp was found to be adenomatous, whether the pathology was tubular or villous or the polyp had high-grade dysplasia or adenocarcinoma.

\section{Aim of the Study}

The aim of our study was to describe the types and patterns of colorectal polyps in patients presenting to a tertiary care referral center in Baghdad. We also assessed the polyp detection rate (PDR), polyps per colonoscopy and adenoma detection rate (ADR).

\section{Patients and Methods}

\subsection{Study Design and Sample}

We conducted a single-institution, descriptive cross-sectional study of 1030 patients who had colonoscopy done at the Endoscopy Unit of Baghdad teaching hospital, IRAQ from the 1st of June 2018 to the 31st of March 2019 after taking verbal consent .

The data collected included: Age, sex, Family history of colorectal malignancies and the diagnosis and indication 
for the colonoscopy.

\subsection{Endoscopically Procedure}

Colonoscopy was carried out after bowel preparation with polyethylene glycol without sedation.

The colonoscopy was performed by the senior gastroenterologist or by a trainee under the direct supervision of senior gastroenterologist using (Olympus LUCERA CLV-260) endoscope and endoscopic diagnosis was made on gross visualization of the lesions.

The location, number, shape, size and histology of polyps detected and removed were documented.

The location of the polyps were defined as distal colon (up to the splenic flexure) and proximal colon (from caecum to splenic flexure).

The polyps are classified according to their morphology to (sessile or pedunculated).

Adenomas are categorized into 3 size groups: smaller than $1 \mathrm{~cm}$ (small), 1 to $2 \mathrm{~cm}$ (moderate), and larger than $2 \mathrm{~cm}$ (large).

In the event of multiple polyps, only the size of the largest was considered for the purposes of analysis.

\subsection{Histopathological Examination}

Biopsies were sent to Department of Pathology for histopathological examination. Histopathology was performed as per the standard protocol of the hospital.

Inclusion criteria

A total of 1030 Iraqi adults patients who underwent a colonoscopy for common indications were selected randomly and included in the study.

Exclusion criteria

1. History of previous colon polyp.

2. History of colorectal malignancy.

3. Hereditary polyposis syndrome.

(To avoid falsely high or low detection rate for CRC and polyps)

\subsection{Statistical Analysis}

Data analysis included descriptive statistics computed for continuous variables, including means, standard deviations (SDs), minimum and maximum values, as well as 95\% confidence intervals (CIs). Frequencies are used for categorical variables.

Data was entered and analyzed using IBM SPSS Statistics 25.0

\section{Results}

During the study period, a total of 1030 patients met the inclusion criteria, the age ranged (17-71)+/-16 years with a median of 44 years (SD 16), 54.4\% $(n=560)$ of the patients were males, $45.6 \%(n=470)$ were females.

Family history of colonic malignancy was positive in $2.9 \%(\mathrm{n}=3)$ of the patients.

The indications for colonoscopy examination included Lower gastrointestinal bleeding $49.5 \%$ ( $n=510)$, Cancer surveillance and follow up for inflammatory bowel disease 15.5\% $(\mathrm{n}=160)$, Altered bowel motion $14.6 \%(\mathrm{n}=150)$, Chronic diarrhea $13.6 \%(\mathrm{n}=140)$, Chronic abdominal pain $4.9 \%(\mathrm{n}=50)$, and Iron deficiency anemia $1.9 \%(\mathrm{n}=20)$, none of the patients in our study had undergone colonoscopy for screening as an indication (Table 1). 
Table 1. Indication for colonoscopy in the study sample

\begin{tabular}{lll}
\hline Indication for colonoscopy & Count & Percent \% \\
\hline Lower gastrointestinal bleeding & 510 & $49.5 \%$ \\
Cancer surveillance for inflammatory bowel disease & 160 & $15.5 \%$ \\
Altered bowel motion & 150 & $14.6 \%$ \\
Chronic diarrhea & 140 & $13.6 \%$ \\
Chronic abdominal pain & 50 & $4.9 \%$ \\
Iron deficiency anemia & 20 & $1.9 \%$ \\
Others & 0 & $0 \%$ \\
Total & 1030 & $100 \%$ \\
\hline
\end{tabular}

Polyp detection rate was $19.4 \%(n=200)$ and the adenoma detection rate was $13.6 \%(n=160)$.

200 patients had detected polyps during colonoscopy, $70 \%(n=140)$ were pedenculated and $30 \%(n=60)$ were sessile (Figure 2).

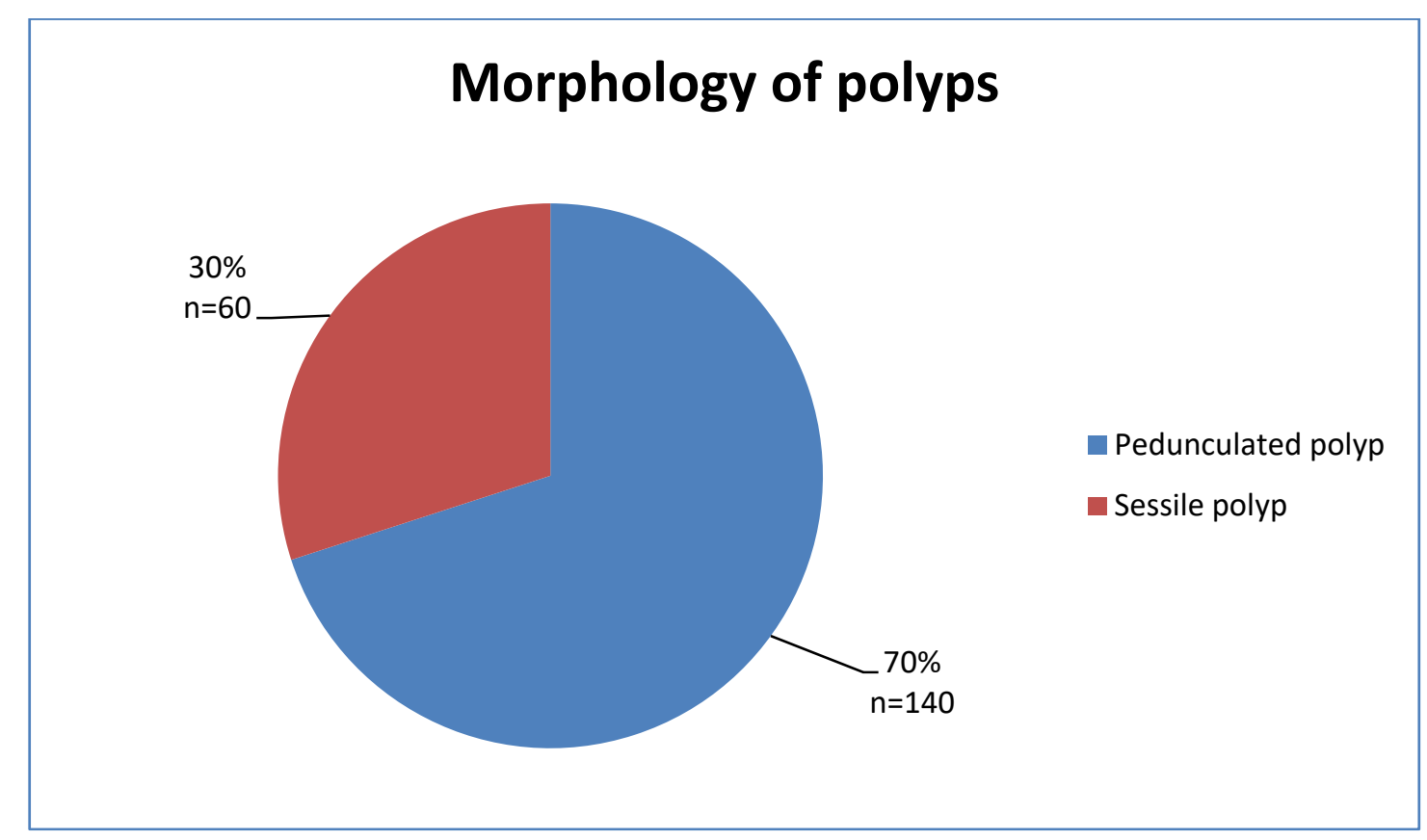

Figure 2. Morphology of colorectal polyps

The number of polyps detected during colonoscopy ranged ( 1 to 7$)$ with $65 \%$ ( $\mathrm{n}=130)$ of patients had single polyp. The majority of the detected polyps were in the distal colon $80 \%(n=160)$, and $20 \%(n=40)$ were in the proximal colon (Figure 3). 


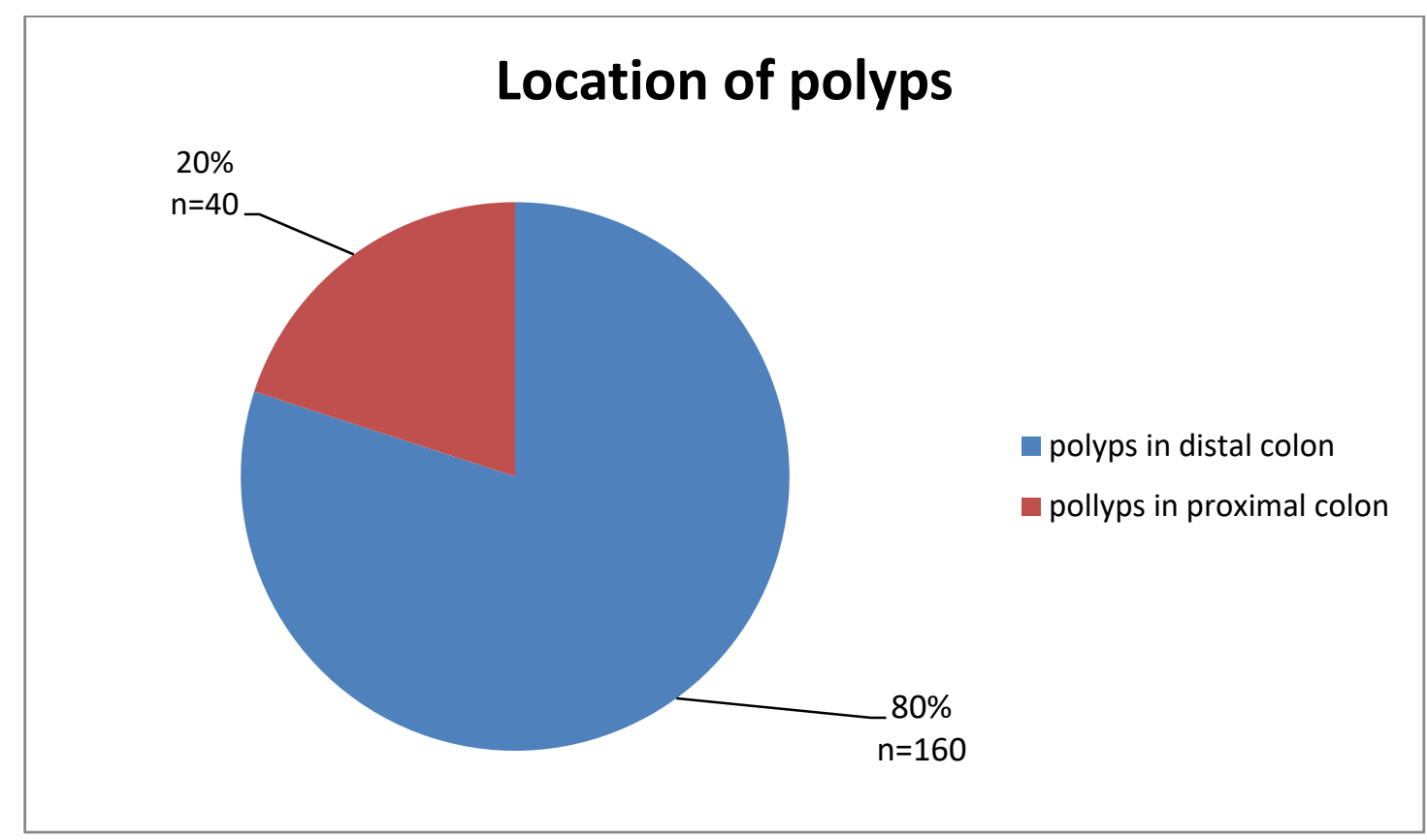

Figure 3. Location of colorectal polyps

Polyps were small in size in $45 \%(n=90)$, moderate in size in 30\% $(n=60)$, and large in size in $25 \%(n=50)$.

Histopathological, of the polyps were neoplastic in $75 \%(\mathrm{n}=150)$, adenomatous in $70 \%(\mathrm{n}=140)$, the most common type of adenomatous polyps was tubular adenoma $40 \%(n=40)$, followed by tubulovillous adenoma $20 \%(n=40)$ and the least common was villous adenoma $10 \%(\mathrm{n}=20)$.

Carcinoma was detected in $5 \%(\mathrm{n}=10)$ of the patients.

Of the 200 patients with detected polyps $25 \%(\mathrm{n}=50)$ had nonneoplastic polyps, the most common was inflammatory polyps $15 \%(\mathrm{n}=30)$, followed by juvenile polyps $5 \%(\mathrm{n}=10)$ and hyperplastic polyps $5 \%(\mathrm{n}=10)$, (Table 2).

Table 2. Histopathology of colorectal polyps

\begin{tabular}{lll}
\hline Histopathology of polyps & Count & Percent \% \\
\hline Tubular adenoma & 80 & $40 \%$ \\
Tubulovillous adenoma & 40 & $20 \%$ \\
Inflammatory polyps & 30 & $15 \%$ \\
Villous adenoma & 20 & $10 \%$ \\
Juvenile polyps & 10 & $5 \%$ \\
Hyperplastic polyps & 10 & $5 \%$ \\
Carcinoma & 10 & $5 \%$ \\
Total & 200 & $100 \%$ \\
\hline
\end{tabular}

Regarding the degree of dysplasia $50 \%(\mathrm{n}=100)$ of the polyps had no dysplasia, $20 \%(\mathrm{n}=40)$ had low grade dysplasia, $5 \%(\mathrm{n}=10)$ had moderate grade dysplasia and 25\% $(\mathrm{n}=50)$ had high grade dysplasia (Figure 4$)$. 


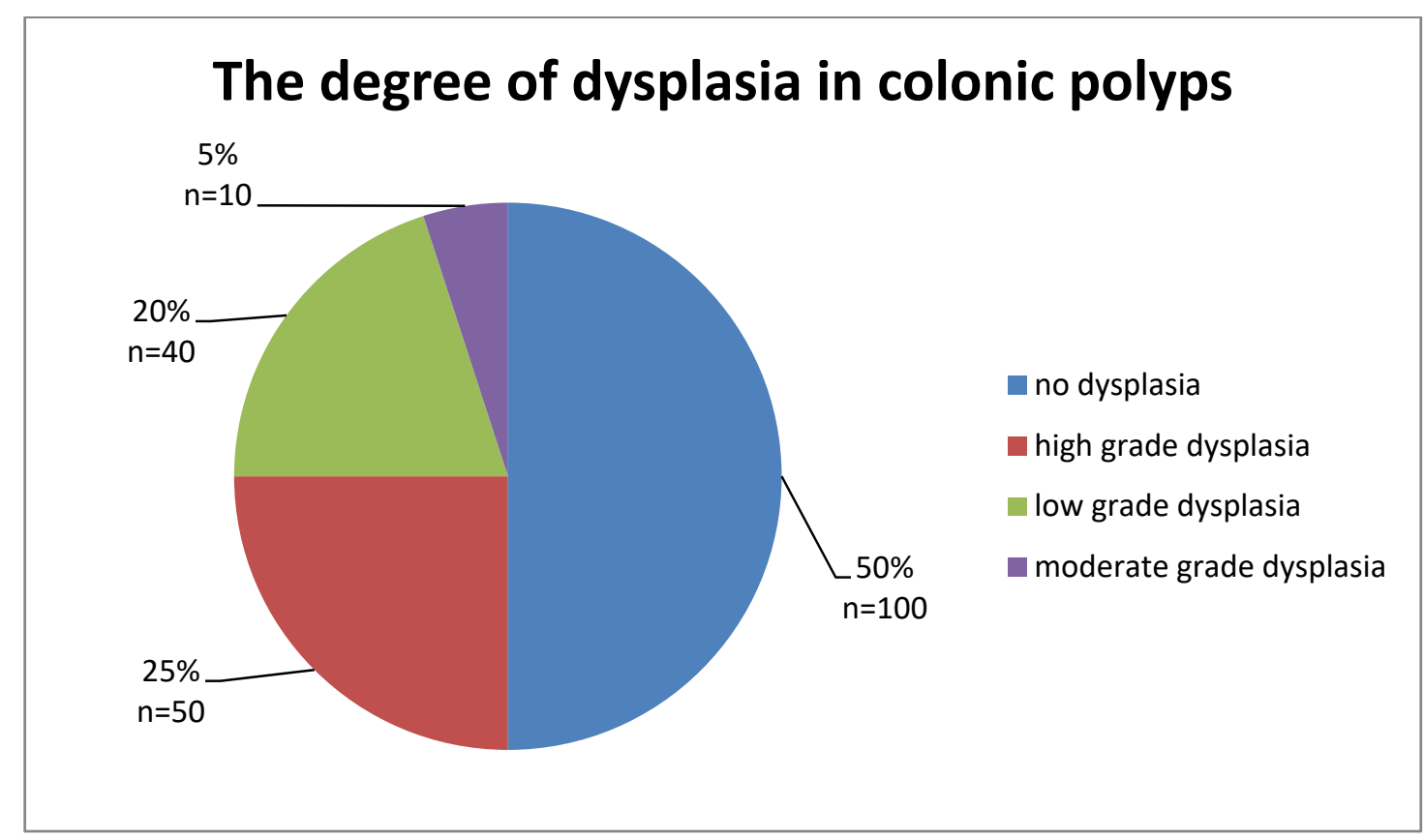

Figure 4. The degree of dysplasia in colorectal polyps

The polyp rate were equal in males and females, the most common indication for colonoscopy associated with polyps detection was lower gastrointestinal bleeding 130(65\%), followed by chronic diarrhea 30(15\%) (Table 3).

Table 3. Indications for colonoscopy in patients with detected polyps

\begin{tabular}{lll}
\hline Indication for colonoscopy in patients with detected polyp & Number & Percent \% \\
\hline Lower gastrointestinal bleeding & 130 & $65 \%$ \\
Chronic diarrhea & 30 & $15 \%$ \\
Cancer surveillance for inflammatory bowel disease & 20 & $10 \%$ \\
Altered bowel motion & 20 & $10 \%$ \\
Others & 0 & $0 \%$ \\
Total & 200 & $100 \%$ \\
\hline
\end{tabular}

The association of the morphology of polyp with histopathological classification was statically significant P-value (0.0001), all the villous adenoma, tubulovillous adenoma, and carcinoma and hyperplastic polyp were pedunculated in morphology.

The entire detected inflammatory polyp were sessile in morphology, the tubular adenomas were mixed in morphology with both pedunculated and sessile morphology (Table 4). 
Table 4. The association of the morphology of polyps with its histopathology

\begin{tabular}{|c|c|c|c|c|c|c|c|c|c|}
\hline & & & \multicolumn{7}{|c|}{ Histopathological classification } \\
\hline & & & TA & VA & TVA & $\mathrm{CA}$ & JP & HPP & IP \\
\hline \multirow{4}{*}{ Morph_ology of polyp } & \multirow{2}{*}{ Pedunculated polyp } & count & 50 & 20 & 40 & 10 & 10 & 10 & 0 \\
\hline & & $\%$ & $4.9 \%$ & $1.9 \%$ & $4 \%$ & $1 \%$ & $1 \%$ & $1 \%$ & $0 \%$ \\
\hline & \multirow{2}{*}{ Sessile polyp } & count & 30 & 0 & 0 & 0 & 0 & 0 & 30 \\
\hline & & $\%$ & $2.9 \%$ & $0 \%$ & $0 \%$ & $0 \%$ & $0 \%$ & $0 \%$ & $2.9 \%$ \\
\hline \multirow{2}{*}{ Total } & & count & 80 & 20 & 40 & 10 & 10 & 10 & 30 \\
\hline & & $\%$ & $7.8 \%$ & $1.9 \%$ & $4 \%$ & $1 \%$ & $1 \%$ & $1 \%$ & $2.9 \%$ \\
\hline P-value & & 0.0001 & & & & & & & \\
\hline
\end{tabular}

The neoplastic polyps were distributed over the proximal and distal colon, while all the nonneoplastic polyps were found in the distal colon (Table 5) (P-value 0.001).

Table 5. The association between the site of polyps and its histopathology

\begin{tabular}{|c|c|c|c|c|c|c|c|c|c|c|}
\hline & & & \multicolumn{7}{|c|}{ Histopathological classification } & \multirow{2}{*}{ Total } \\
\hline & & & $* \mathrm{TA}$ & $* \mathrm{VA}$ & $*$ TVA & $* \mathrm{CA}$ & *JV & *HP & $*$ IP & \\
\hline \multirow{4}{*}{ Site of polyp } & \multirow{2}{*}{ Proximal colon } & Count & 30 & 0 & 10 & 0 & 0 & 0 & 0 & 40 \\
\hline & & $\%$ & $2.9 \%$ & $0 \%$ & $1 \%$ & $0 \%$ & $0 \%$ & $0 \%$ & $0 \%$ & $3.9 \%$ \\
\hline & \multirow{2}{*}{ Distal colon } & Count & 50 & 20 & 30 & 10 & 10 & 10 & 30 & 160 \\
\hline & & $\%$ & $4.9 \%$ & $1.9 \%$ & $2.9 \%$ & $1 \%$ & $1 \%$ & $1 \%$ & $2.9 \%$ & $15.5 \%$ \\
\hline \multirow{2}{*}{ Total } & & Count & 80 & 20 & 40 & 10 & 10 & 10 & 30 & 1030 \\
\hline & & $\%$ & $7.8 \%$ & $1.9 \%$ & $3.9 \%$ & $1 \%$ & $1 \%$ & $1 \%$ & $2.9 \%$ & $100.0 \%$ \\
\hline P-value & & 0.001 & & & & & & & & \\
\hline
\end{tabular}

\section{Discussion}

Colorectal polyp prevalence differs between different countries.

The importance of knowing the distribution of colorectal polyp in each country is because it may affect the efficacy of screening programs and also the prevalence of adenomas that roughly equivalent to the risk of colorectal malignancies (Patel K\& Hoffman NE.2001), (Johannsen, Momsen, \& Jacobsen, 1989).

In our study the polyp detection rate (PDR) was (19.4\%) and the adenoma detection rate (ADR) was (13.6\%).

These results were compared with other countries, in Saudi Arabia the PDR was 20.8\% and ADR was 8.1\% (Majid, Othman, Nahla, Nazia, \& Abdulrahman, 2014).

The PDR was pretty close in our study but the ADR was higher than Saudi Arabia.

In Oman the ADR was (12.1\%) (Ashktorab, Brim, Al-Riyami, \& Date, 2008) while in Iran the ADR was (33\%) (Alireza Delavari, Faraz Bishehsari \& Hamideh Salimzadeh, 2014) and in Kuwait the ADR was (10\%) (Al-Enezi \& Alsurayei, 2010).

In western countries the ADR was much higher, a retrospective chart review from Mayo Clinic, Arizona, found that the ADR reached up to $42 \%$ for some gastroenterologists (Boroff, Gurudu, \& Hentz, 2013), while in Germany was $31.7 \%$ (Schramm, Mbaya, \& Franklin, 2015), This association between adenoma detection rate reflects the incidence of colon cancer in these geographical areas.

The polyps were detected equally in both sexes $50 \%(\mathrm{n}=10)$ for each.

The most common indication for colonoscopy in our population sample was lower gastrointestinal bleeding $49.5 \%$ $(\mathrm{n}=51)$, and it's the most common indication in patients with detected polyps $65 \%(\mathrm{n}=13)$, of note screening colonoscopy as an indication for colonoscopy was absent in our sample. 
The most common type of detected adenoma in our study was tubular adenoma $40 \%(\mathrm{n}=80)$, followed by tubulovillous $20 \%(n=40)$ and villous adenoma $20 \%(n=40)$.

A similar study was done in gastroenterology and Hepatology teaching hospital-Baghdad- Iraq shows that tubulovillous adenoma was the most common type (62.4\%) which was inconsistent with our study (Kerbala Journal of Medicine, 2006).

While a study in Saudi Arabia shows similar results with the most common type of adenoma was tubular adenoma (56.6\%) (Almadi, Allehibi, Aljebreen, \& Alharbi, 2019).

In a study in USA Tubular adenomas represent $\sim 75 \%$ to $85 \%$ of adenomatous polyps (Amersi \& Agustin, 2005).

In our study $80 \%(\mathrm{n}=16)$ of the detected polyps were in the distal colon, a similar studies in Saudi Arabia (Almadi, Allehibi, \& Aljebreen, 2019), Iran (Geramizadeh \& Keshtkar-Jahromi, 2013), Nigeria (Alatise, Arigbabu, \& Agbakwuru, 2014) and China (Zhou \& Zhang, 2017) show similar results.

The association between the age, type of polyp, its size, number and the degree of dysplasia was statistically not significant, probably due to small size of the study sample.

\section{Conclusion}

The polyp detection rate was (19.4\%) and adenoma detection rate was (13.6\%).

The most common type of adenoma detected during colonoscopy was tubular adenoma.

The majority of polyps were detected in distal colon.

The association between the age, type of polyp, its size, number and the degree of dysplasia was statistically not significant, probably due to small size of the study sample.

\section{Competing Interests Statement}

The authors declare that there are no competing or potential conflicts of interest.

\section{References}

Alatise, O. I., Arigbabu, A. O., Agbakwuru, A. E., Lawal, O. O., Sowande, O. A., Odujoko, O. O., ... \& Ojo, O. (2014). Polyp prevalence at colonoscopy among Nigerians: A prospective observational study. Nigerian journal of clinical practice, 17(6), 756-762. https://doi.org/10.4103/1119-3077.144391

Al-Enezi, S. A., Alsurayei, S. A., Ismail, A. E., Aly, N. Y. A., Ismail, W. A., \& Abou-Bakr, A. A. (2010). Adenomatous colorectal polyps in patients referred for colonoscopy in a regional hospital in Kuwait. Saudi journal of gastroenterology: official journal of the Saudi Gastroenterology Association, 16(3), 188. https://doi.org/10.4103/1319-3767.65194

Almadi, M. A., Alharbi, O., Azzam, N., Wadera, J., Sadaf, N., \& Aljebreen, A. M. (2014). Prevalence and characteristics of colonic polyps and adenomas in 2654 colonoscopies in Saudi Arabia. Saudi journal of gastroenterology: official journal of the Saudi Gastroenterology Association, 20(3), 154. https://doi.org/10.4103/1319-3767.132986

Almadi, M. A., Allehibi, A., Aljebreen, M. A., Alharbi, O. R., Azzam, N., \& Aljebreen, A. M. (2019). Findings during screening colonoscopies in a Middle Eastern cohort. Saudi journal of gastroenterology: official journal of the Saudi Gastroenterology Association, 25(1), 20. https://doi.org/10.4103/sjg.SJG_353_18

Amersi, F., Agustin, M., \& Ko, C. Y. (2005). Colorectal cancer: epidemiology, risk factors, and health services. Clinics in colon and rectal surgery, 18(3), 133. https://doi.org/10.1055/s-2005-916274

Anthony, F., Eugene, B., Dennis, K., Stephen, H., Dan, L., Jameson, J., ... \& Houston, B. (2018). Harrison's principles of internal medicine (20th ed., p.572).

Ashktorab, H., Brim, H., Al-Riyami, M., Date, A., Al-Mawaly, K., Kashoub, M., ... \& Raeburn, S. (2008). Sporadic colon cancer: mismatch repair immunohistochemistry and microsatellite instability in Omani subjects. Digestive diseases and sciences, 53(10), 2723-2731. https://doi.org/10.1007/s10620-007-0189-3

Boroff, E. S., Gurudu, S. R., Hentz, J. G., Leighton, J. A., \& Ramirez, F. C. (2013). Polyp and adenoma detection rates in the proximal and distal colon. Official journal of the American College of Gastroenterology| ACG, 108(6), 993-999. https://doi.org/10.1038/ajg.2013.68

Colorectal cancer [Internet]. (2018). The global cancer observatory. Retrieved 2 November 2019, from https://gco.iarc.fr/today/data/factsheets/cancers/10_8_9-Colorectum-fact-sheet.pdf 
Delavari, A., Bishehsari, F., Salimzadeh, H., Khosravi, P., Delavari, F., Nasseri-Moghaddam, S., ... \& Malekzadeh, R. (2014). Adenoma detection rates in an opportunistic screening colonoscopy program in Iran, a country with rising colorectal cancer incidence. BMC gastroenterology, 14(1), 1-6. https://doi.org/10.1186/s12876-014-0196-8

Feldman, M., Friedman, L. S., \& Brandt, L. J. (Eds.). (2016). Sleisenger and Fordtran's gastrointestinal and liver disease E-book: pathophysiology, diagnosis, management (10th ed.). Elsevier.

Garborg, K., Holme, Ø., Løberg, M., Kalager, M., Adami, H. O., \& Bretthauer, M. (2013). Current status of screening for colorectal cancer. Annals of oncology, 24(8), 1963-1972. https://doi.org/10.1093/annonc/mdt157

Geramizadeh, B., \& Keshtkar, J. M. (2013). Pathology of colorectal polyps: a study from South of Iran. Ann Colorectal Res., 1(2), 60-62. https://doi.org/10.17795/acr-12555

Johannsen, L. G. K., Momsen, O., \& Jacobsen, N. O. (1989). Polyps of the large intestine in Aarhus, Denmark. Scandinavian journal of gastroenterology, 24(7), 799-806. https://doi.org/10.3109/00365528909089217

Muto, T., Bussey, H. J. R., \& Morson, B. C. (1975). The evolution of cancer of the colon and rectum. Cancer, 36(6), 2251-2270. https://doi.org/10.1002/cncr.2820360944

Nouraie, M., Hosseinkhah, F., Brim, H., Zamanifekri, B., Smoot, D. T., \& Ashktorab, H. (2010). Clinicopathological features of colon polyps from African-Americans. Digestive diseases and sciences, 55(5), 1442-1449. https://doi.org/10.1007/s10620-010-1133-5

Patel, K., \& Hoffman, N. E. (2001). The anatomical distribution of colorectal polyps at colonoscopy. Journal of clinical gastroenterology, 33(3), 222-225. https://doi.org/10.1097/00004836-200109000-00011

Sayah, A. H., Talabani, A. D., Shubber, H. A., M AL-Khalidi, N., \& Jarallah, S. (2006). Colorectal polyps Clinical, Endoscopic, and Histopathological features. Kerbala Journal of Medicine, 1, 17-26.

Schramm, C., Mbaya, N., Franklin, J., Demir, M., Kuetting, F., Toex, U., ... \& Steffen, H. M. (2015). Patient-and procedure-related factors affecting proximal and distal detection rates for polyps and adenomas: results from 1603 screening colonoscopies. International journal of colorectal disease, 30(12), 1715-1722. https://doi.org/10.1007/s00384-015-2360-1

Vişovan, I. I., Tanşau, M., Ciobanu, L., Pascu, O., \& Tanşau, A. (2014). Increasing prevalence of right-sided colonic adenomas in a high-volume endoscopy department in Romania: implications for colorectal cancer screening. Journal of Gastrointestinal \& Liver Diseases, 23(2). https://doi.org/10.15403/jgld.2014.1121.232.iiv1

Zhou, L., Zhang, H., Sun, S., Huang, M., Liu, J., Xu, D., ... \& Wu, J. (2017). Clinical, endoscopic and pathological characteristics of colorectal polyps in elderly patients: Single-center experience. Molecular and clinical oncology, 7(1), 81-87. https://doi.org/10.3892/mco.2017.1284

\section{Copyrights}

Copyright for this article is retained by the author(s), with first publication rights granted to the journal.

This is an open-access article distributed under the terms and conditions of the Creative Commons Attribution license (http://creativecommons.org/licenses/by/4.0/). 